\title{
Etnotrilhas metropoéticas
}

\author{
Eduardo Fernandes Araújo
}

CAIAFA, J.

Trilhos da cidade, viajar no metrô

do Rio de Janeiro.

Rio de Janeiro, 7Letras, 392 p., 2013.

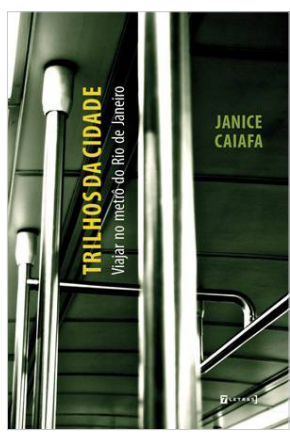

Resumo: Essa pesquisa etnográfica desenvolvida no sistema metroviário do Rio de Janeiro parte da hipótese de que o metrô é uma heterotopia, um lugar que contrasta com o fundo caótico dos centros urbanos por thes oferecer alguma noção de ordenamento e previsibilidade. o entanto, as políticas públicas de concessão, apropriação e uso desse lugar privilegiado têm posto em crise seu aspecto heterotópico, deteriorando, inclusive, seu conspícuo potencial para ser ambiente instigante de comunicabilidades e sociabilidades.

Palavras-chave: etnografia; metrô; heterotopia.

Abstract: Metropoetic Ethnotrails - This ethnographic research conducted in Rio de Janeiro's metro system is based on the hypothesis that the subway is a heterotopy, a place whose order and predictability are in stark contrast with the chaotic background of urban centers. Nonetheless, public policies on franchise, appropriation and use of this outstanding place have cast doubts on its heterotopic nature, and even deteriorated its conspicuous potential to be a stimulating environment for communication and social skills.

Keywords: ethnography; subway; heterotopy.

A autora, Janice Caiafa, é poeta e pesquisadora, professora associada da Escola de Comunicação da Universidade Federal do Rio de Janeiro, com doutorado em Antropologia pela Universidade de Cornell, EUA. Realizou, como organizadora, Comunicação e sociabilidade, 2007 (Ed. Mauad); como pesquisadora, Nosso século XXI, 2000 
(Ed. Relume Dumará), Jornadas urbanas, 2002, e Aventura das cidades, 2007 (Ed. FGv); como poeta, Fôlego, 1998, Cinco ventos, 2001, Ouro, 2005 e Estúdio, 2009 (Ed. 7Letras), entre outros. É também tradutora, já tendo publicado Crônicas dos índios Guayaki de Pierre Clastres, 1995, com Tania Lima (Ed. 34), e As rosas de Reiner Maria Rilke, 2012 (Ed. 7 Letras). Tem inúmeros artigos divulgados em revistas científicas nacionais e internacionais, colaborando, inclusive, com a revista Galáxia, com Humanos e máquinas no metrô (v. 11, n. 21, 2011) e Comunicação e sociabilidade nos cinemas de estação, com Talitha Ferraz (v. 12, n. 24, 2012).

Com a recente publicação de Trilhos da cidade, viajar no metrô do Rio de Janeiro, Caiafa nos convida a uma reflexão política dos modos de comunicabilidade emergentes de espaços urbanos que também são dispositivos de organização da sociabilidade, aqui especificamente instanciados a partir de uma análise etnológica do sistema de trens metropolitanos do Rio, inspirada em Um etnólogo no metrô e O metrô revisitado, ambos de Marc Augé.

Essa vivência antropológica, cuidadosamente documentada e relatada no livro, procura apresentar os aspectos sincrônicos e diacrônicos de se viajar de metrô ao tentar apreender esse cotidiano, mostrando seus recortes contextuais mais amplos sobre questões humanas (afetivas, sociais, artísticas, econômicas, religiosas, científicas, etc.) da cidade e do país; enfim, um convite a considerar problemas muitas vezes insuspeitos da nossa presentidade e que vão espontaneamente emergindo das interações e das falas em coletividade. Essa é uma sensibilização típica do método etnográfico, exemplificado nessa obra de desejável interesse para comunicólogos e antropólogos, assim como para o público em geral interessado em crítica política.

Embora Caiafa não enuncie explicitamente sua hipótese de trabalho, seu texto literariamente agradável não dificulta essa detecção: a pesquisa mergulha no contexto a ser observado, guiando-se pela hipótese de que o metrô, como equipamento urbano inicialmente projetado para mero transporte de passageiros, é, na verdade, por se supor uma héterotopie - no sentido que Michel Foucault dá a "um lugar que contesta, em alguma medida, os lugares ordinários de uma sociedade por apresentar características especiais"-, uma ambiência movente de comunicogêneses significativas para a conjugação da vida das pessoas nas grandes cidades. O fio condutor da apresentação desses resultados respeita a lógica do método etnográfico e seu imperativo de observação participante, lançando mão de questionários semiestruturados, análise da conversação e dos modos de discurso, além da integração cada vez mais assídua de recursos e registros audiovisuais.

Uma das características mais promissoras da etnografia merece ser sublinhada aqui: a disposição, não apenas para visitar os vieses de vivência, mas antes, e principalmente, para se compenetrar naqueles contextos de (des)confortos existenciais. É essa disposição de intropatia (como em Einfühlung, empatia desde dentro, de entrar na experiência do outro, anulando a noção de alteridade como dicotomia ou oposição, a fim de viver na própria pele o desafio de estar-aí, de se retornar quase indiviso com aquele antes-um-outro mediante diálogo semiótico), o que aciona no aspirante a viver-etnologia aquela porosidade 
estética para o corpensamento (ou ainda Körperdenken, corpo(coração)+pensamento, e não apenas com a cabeça ou a razão), holisticamente imerso e em constante prontidão interativa em relação aos demais corpensantes em fluxo, capaz de viabilizar uma aderência honesta entre o que acontece em cada um dos aquis-e-agoras em rede, e apto assim a providenciar uma crítica dessas medialidades de envolvimento ressoante, indo muito além do confortável, e em geral boçal e inútil pensamento de poltrona ou cientificismo de gabinete.

Caiafa não articula nenhum desses dois conceitos em seu livro, mas é perfeitamente possível identificar, para além dos simples nomes ou palavras, a presença vívida desses entendimentos em inúmeros momentos da narrativa, como por exemplo:

O metrô tem uma história de percalços, desde que se começou a aventar construí-lo e até hoje, mas é ainda um meio de transporte com que contamos em vários momentos e onde experiências singulares são possíveis. É um lugar onde construímos interfaces com as máquinas, em que estabelecemos relações com os companheiros de viagem, cultivamos o silêncio e a observação, além de nos exercitarmos num treino ético, e sermos acolhidos por uma estética ativa nesse ambiente que também ajudamos a produzir com a nossa presença. (p. 371)

Como se faz isso? Ambicione devorar deliciosa e demoradamente todo Trilhos de Janice Caiafa. Iniciada em 2005, a investigação queimou as pestanas para ser o mais inclusiva possível, sistematizando uma revisão documental rigorosa, consultando manuais e especialistas jurídicos e técnicos, conversando não só com usuários, mas também com funcionários, engenheiros, comerciantes e, constrangedoramente, também com os administradores da concessionária que explora temporariamente a prestação desse serviço público no metrô do Rio: e que a certa altura da observação e registro de dados reagiram, temerosa e titanicamente, na articulação da sabotagem e no quase encerramento e comprometimento de toda a pesquisa.

Não obstante, Janice deu um jeito e juntou coragem e engenho para remanejar as abordagens metodológicas e concluir sua obra, e o fez de modo magistral. A narrativa completa está na introdução do livro. Também na introdução, a autora coalha o plasma ambimental (mente-ambiente) em meio ao qual a pesquisa percorre flutuações despercebidas, e oferece uma brevíssima, porém precisa, descrição do funcionamento do metrô do Rio, acompanhada de infográficos de rápida compreensão.

Os capítulos do livro foram estruturados a fim de evidenciar aspectos sincrônicos e diacrônicos do cotidiano viário especificamente vivido desde dentro dessa ambimental comunicogênica chamada metrô, e dentro do qual transitamos e também encontramos as condições de possibilidade e de efetivação - mesmo que "fraca" ou "líquida" - de tantos e diferentes vínculos comunicativos não-automatizados e outrora talvez impensáveis. Os doze capítulos podem ser diagramados, para fins didáticos como guia de leitura, em cinco gestos ou etapas etnográficas.

O primeiro gesto consiste nos dois primeiros capítulos, onde claramente se acompanham o planejamento do projeto de pesquisa, a montagem da estratégia 
metodológica, o critério de levantamento documental, e a revisão bibliográfica comparativa acerca de outros empreendimentos investigativos sobre o metrô das grandes cidades. Por fim, faz um esboço de possíveis categorias (ou modos de ser), desse equipamento urbano moderno, e em recursão às quais a pesquisa pode se referenciar e refletir criticamente acerca do papel do transporte coletivo nas metrópoles, iluminando questões bem concretas da cidade do Rio de Janeiro. São essas as categorias elencadas sobre a paradoxal imagem de uma solidão povoada por ritmos urbanos: o metrô em seu modo de ser espaço de regulação, de conversação, de leitura, de companhia silenciosa, de ensimesmamento em prontidão ciente, e também como equipamento de uso público comum.

O segundo gesto compreende os capítulos três, quatro e cinco. Essa trilogia busca contrastar e ressaltar os aspectos sincrônicos a partir da diacronia, ou seja, começa expondo a circunstância espacial e tecnológica das instalações do metrô, e depois conta como foi feita a transição entre o antigo e o novo sistema de bilhetagem e a cobrança dos diversos tipos de passagem, detalhando as percepções dos usuários sobre tarifação, integração e gratuidade.

O terceiro gesto se parece com uma pausa, contando apenas com o capítulo seis, em razão de ser o momento oportuno para um primeiro ensaio de crítica política aos regimes de uso e consumo no metrô, aos caminhos assumidos pela publicidade e o marketing na exploração da agregação de valor ao ato de ir e vir.

O quarto gesto, que consta dos capítulos sete, oito e nove, retoma a explanação dos aspectos etnográficos, agora destacando as trajetividades diacrônicas a partir da sincronia, isto é, relembra os caminhos históricos ou biográficos da criação e da implantação do metrô no Rio de Janeiro, põe em relevo os comentários e tomadas de partido de inúmeros atores em rede, que participam de seu funcionamento e de sua manutenção, e elabora, com a matéria-prima desses depoimentos e testemunhos, toda uma imageria ${ }^{1}$ do que significa a experiência de poder baldear entre as duas linhas para os cidadãos, e o quanto contam com isso diariamente no agenciamento de seus modos de vida para com todos os demais espaços emaranhados da cidade; em suma, exibe como esses atores reinauguram e reinventam os lugares de frequentação e habituação, a exemplo dos antigos cinemas de estação. A essa altura, a autora retoma sua caracterização do metrô como uma heterotopia.

O quinto e último gesto abarca os capítulos dez, onze e doze, que se apresentam como ensaios de crítica política mais densa. Neles discute-se as vicissitudes da conscientização para acesso cidadão aos assentos preferenciais, e da implantação de um vagão para uso exclusivo das mulheres com suas questões de discurso de gênero e igualdade aí implicadas, para encerrar observando como o metrô participa, hoje, de uma maneira que parece irreversível e inexorável, das convergências comerciais, românticas, artísticas (como o surpreendente fenômeno da caverna do Batman), religiosas, carnavalescas, etc. O conjunto dos três capítulos derradeiros vem finalmente arrematar a justificativa do metrô

1 Trata-se da produção de imaginário de dentro para fora, iconomorfias endógenas, a eletricidade da imaginação pondo o imaginário em dinamismo para ressignificar as brechas de aprendizagem, oportunizar fresca configuração semiótica a singularidades potencialmente reincidentes. 
como meio heterotópico, a hipótese que deu luz à pesquisa: o metrô é um lugar exótico porque parece pôr alguma ordem ou figurar como uma segurança previsível em meio à fragmentação urbana e ao caos contemporâneos.

O exercício hipotético aqui se sabe como muito iniciático, não uma hipótese cuja razoabilidade pragmática já possa ser amadurecidamente, deduzida em seus complexos meandros e conjuntos de consequências práticas, mas sim uma proto-hipótese que não comete aquela ingênua arrogância de pressupor a natureza ou modo de ser das variantes a serem rastreadas; ao contrário, esforça-se, por enquanto, em tão-só entrever nuançadas possibilidades a serem tematicamente desenvolvidas. Mesmo quando aponta para categorias sugeridas por pesquisas anteriores, como por exemplo, àquelas elencadas no capítulo dois, somente o faz mediante a sóbria aceitação de sua inclusão como referência em espera e, portanto, sujeita a chuvas e trovoadas; porém, jamais como conceitos a serem aplicados na reflexão crítica, porque eles mesmos estão sujeitos à crítica de suas condições de produção como conceitos ou discursos legitimadores; o que pode ser constatado no final dos capítulos nove e dez, sobre a crise da heterotopia, no momento em que o metrô deixa de ser um paradigma organizativo em meio ao caos urbano e passa a ser, ele mesmo, tão ou mais desordenado que a cidade ao seu redor:

Para os usuários, a situação era totalmente nova: o metrô costumava ser um lugar em que o caos da cidade não entrava, ou só episodicamente, e agora estava extremamente tumultuado e era objeto de medidas oficiais e questionamentos.(p. 296)

Os clássicos pioneiros do método etnográfico, notadamente o teuto-americano kwakiutlês, Franz Boas, e o anglo-polaco trobriandês, Bronislaw Malinowski, não apenas postularam o resgate desse diálogo semiótico, como também e muito pragmaticamente se aventuraram a extrair dele suas máximas consequências; no entanto, Boas permaneceu minuciosamente diacrônico com seus bailarinos, ao passo que Malinowski se restringiu ao obsessivamente sincrônico dos seus argonautas.

O livro Trilhos da cidade, viajar no metrô do Rio de Janeiro ilustra o potencial de desenvolvimento crítico de um empreendimento antropológico e comunicológico originalmente brasileiro, salientando muitas qualidades do amadurecimento do método etnográfico durante o último século. O corpensamento vivenciado na imersão intropática pode dar margem a uma imageria ambimental de vínculos comunicativos inesperados, somente viáveis pela disposição de ressonância com o cipoal de dimensões afetivas, comportamentais e cognitivas das vozes e grupos humanos que estão sendo observados e degustados.

Os dançarinos decapitáveis de Boas são personagens descritos de maneira meticulosamente linear, já os argonautas aprimitivos de Malinoswski padecem de uma intensa emotividade extática e estática. Mas, agora contamos com os metronautas corpensantes de Caiafa, ela mesma uma metronauta corpensante, atuando nos fluxos e trajetivas em rede, e que prefere olhar para os formatos já estabelecidos como vestígios ou índices de potencialidades morfogênicas outras, mais profundas e grávidas 
de novas singularidades atualizáveis, ou seja, de novos modos de ser e de habitar a existência, enquanto vamos estabelecendo vínculos éticos com antes-uns-outros, porém agora esteticamente todos juntos e misturados:

A questão do cultivo ético no espaço público e partilhado do metrô é uma delas. A convivência com desconhecidos no espaço urbano configura-se, a meu ver, como uma oportunidade para o exercício de uma ética e me interesso pelas características que esse exercício assume no metrô do Rio de Janeiro. Esta questão encontra uma outra, a da estética no metrô, que vai sendo apresentada ao longo do livro e se esclarece mais no capítulo final. (p. 43)

Enfim, estar presencialmente em campo e sentir no próprio corpo cada canto, e se é o caso de estarmos lidando com uma obra de implicações ao mesmo tempo políticas e poéticas, científicas e éticas, parece então pertinente concluir esta resenha citando o poeta persa Jalal Rumi, xeique sufi do século XIII, para insinuar arqueologicamente que essa ideia de corpensar a intropatia de potenciais imagerias ambimentais já havia se avatarizado, ao menos uma única vez, em um passado não muito distante e em um contexto de intensos jogos de poderes soberanos e titânicos. Porém ainda não tão dinâmica e politicamente consequente quanto nas etnotrilhas metropoéticas de Janice Caiafa, cujo sobrenome tem a mesma origem árabe que o do teólogo islâmico, que canta de corpo inteiro:

Cansado das formas

Voltei às qualidades.

Cada uma delas diz:

- Sou mar de azuis-turquesas,

Mergulha já em mim!

Eduardo Fernandes Araújo é designer gráfico e doutorando em Comunicação e Semiótica na PUC-SP, com bolsa da Fapesp, sob a orientação de Lucrécia D'Aléssio Ferrara.

dubol@yahoo.com

\section{Referências}

FOUCAULT, M. Outros espaços. In Estética: literatura e pintura, música e cinema - Ditos e escritos III. Rio de Janeiro: Forense Universitária, 2001.

RUMI, J. Selected poems from the Divan-e Shams-e Tabrizi (Along with the original Persian \pm 1240 ). Trad. Reynold Nicholson. Washington DC (EUA), 2001. 